Ifibrary, N.W. Bidg

OCT 291963

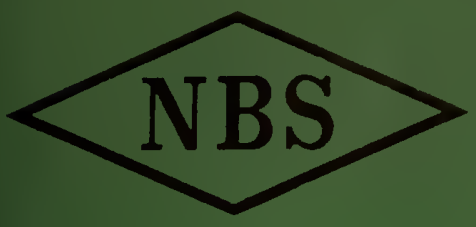

Eechnical Note No.200

\title{
CARBON RESISTORS FOR CRYOGENIC LIQUID LEVEL MEASUREMENT
}

RICHARD C. MUhLENhaupt AND PEter SMElSER

U. S. DEPARTMENT OF COMMERCE NATIONAL BUREAU OF STANDARDS 


\section{THE NATIONAL BUREAU OF STANDARDS}

\section{Functions and Activities}

The functions of the National Bureau of Standards are set forth in the Act of Congress, March 3, 1901, as amended by Congress in Public Law 619, 1950. These include the development and maintenance of the national standards of measurement and the provision of means and methods for making measurements consistent with these standards; the determination of physical constants and properties of materials; the development of methods and instruments for testing materials, devices, and structures; advisory services to government agencics on scientific and technical problems; invention and development of devices to serve special needs of the Government; and the development of standard practices, codes, and specifications. The work includes basic and applied research, development, engineering, instrumentation, testing, evaluation, calibration services, and various consultation and information services. Research projects are also performed for other government agencies when thie work relates to and supplements the basic program of the Bureau or when the Bureau's unique competence is required. The scope of activities is suggested by the listing of divisions and sections on the inside of the back cover.

\section{Publications}

The results of the Bureau's research are published either in the Bureau's own series of publications or in the journals of professional and scientific societies. The Bureau publishes three periodicals available from the Government Printing Office: The Journal of Research, published in four separate sections, presents complete scientific and technical papers; the Technical News Bulletin presents summary and preliminary reports on work in progress; and the Central Radio Propagation Laboratory Ionospheric Predictions provides data for determining the best frequencies to use for radio communications throughout the world. There are also five series of nonperiodical publications: Monograplis, Applied Mathematics Series, Handbooks, Miscellaneous Publications, and Technical Notes.

A complete listing of the Bureau's publications can be found in National Bureau of Standards Circular 460, Publications of the National Bureau of Standards, 1901 to June 1947 (\$1.25), and the Supplement to National Bureau of Standards Circular 460, July 1947 to June 1957 (\$1.50), and Miscellaneous Publication 240, July 1957 to June 1960 (includes Titles of Papers Published in Outside Journals 1950 to 1959) (\$2.25); available from the Superintendent of Documents, Government Printing Office, Washington D.C. 20402. 


\title{
NATIONAL BUREAU OF STANDARDS \\ Eechnical Note 200 \\ Issued October 9, 1963
}

\section{CARBON RESISTORS FOR CRYOGENIC \\ LIQUID LEVEL MEASUREMENT}

\author{
Richard C. Muhlenhaupt and Peter Smelser \\ Cryogenic Engineering Laboratory Division \\ National Bureau of Standards \\ Boulder, Colorado
}

NBS Technical Notes are designed to supplement the Bureau's regular publications program. They provide a means for making available scientific data that are of transient or limited interest. Technical Notes may be listed or referred to in the open literature.

For sale by the Superintendent of Documents, U. S. Government Printing Office Washington, D.C. 20402

PRICE 25 CENTS. 


\section{National Bureau of Stancands}

\section{AUG $5 \quad 1305$}

130,889

\section{IMPORTANT NOTICE}

NATIONAL BUREAU OF STANDARDS REPORTS ore usually preliminory or progress occounting docu. ments intended for use within the Government. Before moteriol in the reports is formolly published it is subjected to odditional evaluotion ond review. For this reoson, the publicotion, reprinting, reproduction, or open-literoture listing of this Report, either in whole or in port, is not outhorized unless permission is obtoined in writing from the Office of the Director, Notional Bureou of Stondords, Woshington 25, D. C. Such permission is not needed, however, by the Government ogency for which the Report hos been specificolly prepored if thot ogency wishes to reproduce odditional copies for its own use. 


\section{CONTENTS}

\section{Page}

1. Introduction. . . . . . . . . . . . . . . . 1

2. Description of Test Apparatus. . . . . . . . . 2

3. Experimental Procedure . . . . . . . . . . 3

4. Discussion of Results . . . . . . . . . . . 4

5. Relative Precision and Reliability of Resistors . . . 5

6. Conclusion . . . . . . . . . . . . . 7

7. Appendix . . . . . . . . . . . . . 7 



\section{CARBON RESISTORS FOR CRYOGENIC LIQUID LEVEL MEASUREMENT}

Richard Muhlenhaupt and Peter Smelser

Data are shown in graphical form. One set of plots presents resistance ratio $\mathrm{R}_{G} / \mathrm{R}_{\mathrm{L}}$ as a function of "warming up" time at various levels of constant power dissipation. A second set of plots presents resistance ratio $R_{L} / R_{O}$ as a function of nominal resistance at various levels of constant power dissipation.

The use of the data and the design of a practical liquid level inidcator are discussed in the appendix.

\section{Introduction}

In the past few years sufficient interest has been shown in the use of ordinary carbon composition resistors for cryogenic liquid level measurement to warrant a study of the various parameters involved in the design of this type of liquid level indicator. Resistors are commonly used for the detection of liquid levels when a simple and inexpensive point sensor is desired and when precise indication and fast time response are not critical requirements.

The principal of operation is based upon (1) the heat transfer characteristics of the resistor in gas and liquid, and (2) the large negative temperature coefficient of resistance which occurs when the resistor is in a cryogenic environment.

The circuitry required for the detection of liquid levels by this method includes a Wheatstone bridge (the liquid level resistor being one of the arms), a power supply, an amplifier, and the desired readout equipment (lightbulb, galvanometer, relay, etc.). 
When a liquid level indicator is to be designed, the following three parameters should be known: the maximum allowable power dissipation, the temperature of the liquid to be detected, and the desired response time (determined by the vaporization $r$ ate and the allowable liquid level drop). If data relating these parameters to design criteria were available, the design of functional liquid level indicators would be facilitated.

Accordingly, tests in liquid nitrogen, hydrogen, and helium were conducted on a number of 0.1 watt (manufactured by Ohmite) and 0.5 watt (from general stock, manufacturer unknown) carbon composition resistors having nominal resistances ranging from 10 to 10,000 ohms. Carbon deposited film 1\% resistors were also included in the test program; these, however, were found to be relatively insensitive to extreme temperature reductions (see figure 1) and are not recommended for liquid level measurement.

The test program is discussed in the following pages, and the results are shown in the accornpanying graphs. In addition, some observations regarding resistor precision and reliability are noted.

\section{Description Of Test Apparatus}

The test apparatus consisted of two major units: the probe assembly and the associated electrical circuitry. Principal components of the probe assembly are shown in figure 2. The guide tube houses a moveable plunger tube which in turn supports the test resistor. An adjustable stop controls the positioning of the test resistor in relation to the liquid-vapor interface, the location of which is determined by the liquid level sensor fastened to the end of the guide tube. A microswitch, actuated when the resistor is passing through the liquid-vapor interface, provides a zero time signal. 
The electrical circuitry is shown in figure 3. A 60 watt, D. C. , constant voltage, power supply provides the necessary power. Resistors $R_{1}, R_{2}, R_{3}$, and either $R_{T}$ or $R_{C}$ form a Wheatstone bridge. Decade box $R_{3}$ is used to balance the bridge when the test resistor is in the circuit, and decade box $R_{C}$ (checking resistor) is used to determine the resistance of $R_{T}$ and to calibrate the recorder. A recorder charts the bridge unbalance as the resistor passes through the liquid-vapor interface. A potentiometer is used to measure the voltage drop across the bridge.

\section{Experimental Procedure}

Twelve 0.1 watt and twelve 0.5 watt carbon composition resistors were tested. For each power rating, three resistors of each value $(10,100,1000$, and 10,000 ohms) were chosen. After the selected resistor was attached to the leads on the plunger tube, its room temperature resistance ( $R_{O}$ in figures 13 and 14 ) was measured with a Wheatstone bridge. Then the travel of the plunger tube was adjusted to permit moving the test resistor from a submerged position to a point slightly above the liquid-vapor interface.

With the sensor in the submerged position, the magnitude of the resistance in liquid ( $R_{L}$ in figures 4 through 12 ) was determined by balancing the bridge, substituting checking resistor $R_{C}$, and adjusting the resistance of $R_{C}$ equal to that of $R_{L}$. A resistance calibration was established by adjusting $\mathrm{R}_{C}$ (while in the circuit) to a number or predetermined resistance levels and recording the resulting recorder deflections.

The actual testing was begun with the test resistor submerged in the liquid bath. The recorder chart drive was turned on, and the plunger tube was quickly raised causing the microswitch to be actuated, which 
momentarily placed a resistance in parallel with $\mathrm{R}_{\mathrm{T}}$ for the zero time indication. When a resistance change of about $5 \%$ had been reached, the chart drive was turned off. During this process, the voltage across the bridge was measured with the potentiometer.

This procedure was repeated three times at approximately the same bridge supply voltage. The supply voltage was then changed to provide a new power level and testing was resumed. When tests had been conducted at three or four different voltage settings, a new resistor was selected and the process repeated.

\section{Discussion of Results}

The data obtained from the test program were plotted in the form of curves which are presented in figures 4 through 14. Each of the first nine graphs (figures 4 through 12 ) show resistance ratio $\left(R_{G} / R_{L}\right)$ as a function of "warming up" time at various levels of power dissipation.

The plots show that level indicating sensitivity improves with increased power dissipation. They also show that sensitivity is increased when the temperature of the resistor's environment is lowered (i. e. , sensitivity is best in helium, next best in hydrogen, and poorest in nitrogen).

It was expected that the ratio $R_{G} / R_{L}$ in the time response curves would begin at unity and continuously approach some lower value; however, for most plots this is not the case. Instead, the ratio becomes larger than unity before dropping to lower values. This suggests that the resistor, after passing through the liquid-vapor interface, senses a lower temperature. At the present time no satisfactory explanation of this behavior has been worked out.

In order to avoid this initial "negative" effect, it is suggested that a resistance ratio of 0.98 (an arbitrary figure that may be adjusted to the designer's requirements) be used as the time response determining 
figure.

It should be noted that: (1) the test conditions could not be identically reproduced for resistors of the same nominal rating, and (2) much of the data was combined in order to reduce the number of final graphs. The plots represent average data derived from three individual runs for each test condition. In addition, the only $10 \mathrm{ohm}$ resistors which gave reasonable response times were those having 0.1 watt nominal rating, and furthermore these gave usable results only when used in helium. Although deviations were observed, it was felt that they were insufficient to impair the usability of the curves.

The final two graphs (figures 13 and 14) show resistance ratio as a function of nominal resistance for several series of resistors operated at various power levels. On these graphs the resistance ratio is the measured resistance in liquid $\left(R_{L}\right)$ divided by the measured resistance at room temperature $\left(R_{O}\right)$, while the abscissas of the graphs represent the nominal resistance rating of the resistors. It will be noted that as the nominal resistance increases or as the temperature of the environment decreases, the resistance ratio becomes greater. In addition, increased power dissipation tends to decrease the resistance rațio. Within experimental error the semi-log plots appear as straight lines. With the help of these graphs it becomes a simple matter to determine the expected magnitude of the resistance in liquid once the following are known:(1) the maximum allowable power dissipation, (2) the nominal rating of the selected resistor, and (3) the liquid to be detected.

5. Relative Precision And Reliability of Resistors The precision of a number of liquid level sensors was determined 
in separate tests conducted at the Cryogenic Engineering Laboratory [1]. The sensors were lowered into a liquid hydrogen bath until a wet indication was noted and then raised until a dry indication was observed, the distance traveled being measured to the nearest.001 inch. From these data a bandwidth denoting the maximum distance between the wet and dry indications for any given sensor was produced. In order to determine how pressurizing the liquid affects the magnitude of the bandwidth, a series of runs were conducted on each sensor at pressures ranging from two to 200 psig.

Among the commercial liquid level indicators evaluated in this manner was a 0.1 watt, $1000 \mathrm{ohm}$ carbon resistor type, (manufactured by Ohmite), which was positioned with its major axis parallel to the liquidvapor interface. The bandwidth was found to vary from 0.015 to 0.122 inch. Bandwidths varying from 0.020 to 0.028 inch were found for a hot wire sensor similarly tested. No simple correlation was found between pressure and bandwidth.

Response time, determined in the same test program, was found to vary from 0.003 to 1.128 seconds for the hot wire sensor, while the response time of resistors in the present program (see Discussion of Results and figures 4 through 12) ranges from about 0.5 to 8.0 seconds.

Although reliability tests were not included in either program, resistors have been frequently used for liquid level sensors at the Cryogenic Engineering Laboratory, and it has been found that their characteristics vary at times. Prolonged thermal cycling, for example,

[1] D. A. Burgeson, W. G. Pestalozzi, and R. J. Richards, "The Performance Of Point Level Sensors In Hydrogen," Advances in Cryogenic Engineering 9, In Press. 
has been known to cause resistance changes of as much as $10 \%$, but this can be corrected by a minor circuit adjustment.

In general, the resistor leads should be cut as short as possible to reduce the effective mass, care should be taken when attaching the lead-out wires because heating can increase the resistance by as much as $10 \%$, and the probe design should provide for liquid drainage away from the resistor.

\section{Conclusion}

The results of the test program show that the time response of resistors is somewhat slower than that of a hot wire sensor. Sensitivity depends upon the allowable power dissipation and the temperature of the liquid being detected, greater sensitivity being obtained when the power is increased or when the temperature of the liquid is decreased. The value of the resistance in liquid depends upon (1) the power dissipation, (2) the ohmic rating of the resistor, and (3) the liquid. Once these three parameters have been selected, the magnitude of the resistance in liquid may be readily determined.

The bandwidth of $1 / 8$ inch for a horizontally mounted resistor is adequate for all but the most precise requirements. Resistors are inexpensive and easy to mount and the associated electrical circuitry can be simple.

It is apparent that ordinary carbon composition $x$ esistors perform reasonably well as liquid level sensors, and within the indicated limits, they are well suited for this purpose.

\section{Appendix}

The bridge components (see figure 15-a) are governed by the following considerations: the power dissipation of the ratio arms should 
be a reasonable value, the resistance ratio $R_{L} / R_{A}$ should be approximately equal to $R_{B} / R_{C}$, and the resistances of $R_{B}$ and $R_{C}$ should be small in relation to the amplifier's input impedance in order that high sensitivity may be obtained.

The design of a practical liquid level indicator will now be considered. Arbitrarily selected parameters are:

(1) maximum allowable power dissipation: 125 milliwatts or less

(2) liquid to be detected: hydrogen

(3) desired time response: two seconds or less. Readily available components are:

(1) power supply: 26.5 volt, D. C. , $600 \mathrm{ma}$

(2) indicator: 6 volt, $150 \mathrm{ma}$, \#47 lightbulb

(3) amplifier: two-stage, transistorized, $Z \approx 5000 \mathrm{ohms}$

(4) balancing potentiometer: $1000 \mathrm{ohm}, 2$ watt.

Figure 9 shows that a 1000 ohm, 0. 5 watt resistor dissipating $115 \mathrm{~m}$ watts satisfies the above criteria, and figure 14 shows that a resistor of this nominal rating will have a resistance ratio $R_{L} / R_{O}$ of about 2. 50. The resistance of $R_{L}$ is then found to be approximately 2500 ohms. When half the resistance of the potentiometer (design null) is added to the resistance of $R_{L}$, the resistance between points " $a$ " and "d" on figure 15-a is 3000 ohms.

In order to find suitable resistance values for the other three arms of the bridge, it is convenient to first find the current in the branch adc. Since 115 milliwatts are dissipated in $R_{L}$,

$$
\begin{aligned}
& I_{\text {adc }}=\sqrt{\frac{115 \mathrm{mw}}{2500 \mathrm{ohm}}}=6.78 \mathrm{ma} \text {, and } \\
& R_{\text {adc }}=\frac{26.5 \mathrm{v}}{6.78 \mathrm{ma}}=3900 \mathrm{ohm} .
\end{aligned}
$$


This leaves 400 ohms for resistor $R_{A}$. A 0.5 watt, 390 ohm resistor (the nearest nominal resistance rating) is therefore selected. The resistance ratio of the two adjacent arms then becomes

$$
\begin{aligned}
R_{\text {ad }} / R_{\text {dc }} & =3000 / 890 \\
& =3.37 .
\end{aligned}
$$

Recalling that high sensitivity will be obtained when the resistance of resistors $R_{B}$ and $R_{C}$ are small compared to the input impedance of the amplifier, a $300 \mathrm{ohm}$ resistor is arbitrarily selected for $R_{B}$. The resistance of $\mathrm{R}_{\mathrm{C}}$ is then calculated from the relation

$$
\mathrm{R}_{\mathrm{B}} / \mathrm{R}_{\mathrm{C}}=\mathrm{R}_{\text {ad }} / \mathrm{R}_{\mathrm{dc}}
$$

or

$$
\begin{aligned}
R_{C} & =300 / 3.37 \\
& =89 \text { ohms. }
\end{aligned}
$$

A $910 \mathrm{ohm}$ resistor is therefore selected for $R_{C}$.

It remains to be determined whether or not these resistors will produce a reasonable power dissipation. The current in this portion of the circuit will be

$$
\begin{aligned}
I_{\text {abc }} & =\frac{26.5 \text { volts }}{391 \text { ohms }} \\
& =68 \mathrm{ma} .
\end{aligned}
$$

With this current, $R_{B}$ will dissipate 1.39 watts, which is somewhat high. This indicates that larger resistors should be used to reduce $I_{a b c}$. If 
$R_{B}$ is 1000 ohms, $R_{C}$ will be about 300 ohms and the power dissipated in the larger resistor will be 0.4 watt. This is below the power rating for the resistor and $R_{a b c}$ is still low when compared with the input impedance of the amplifier.

The resistors finally selected for the bridge are

$$
\begin{aligned}
& R_{S}: 1000 \text { ohm, } 0.5 \text { watt } \\
& R_{A}: 390 \mathrm{ohm}, 0.5 \text { watt } \\
& R_{B}: 1000 \text { ohm, } 0.5 \text { watt } \\
& R_{C}: 300 \text { ohm, } 0.5 \text { watt. }
\end{aligned}
$$




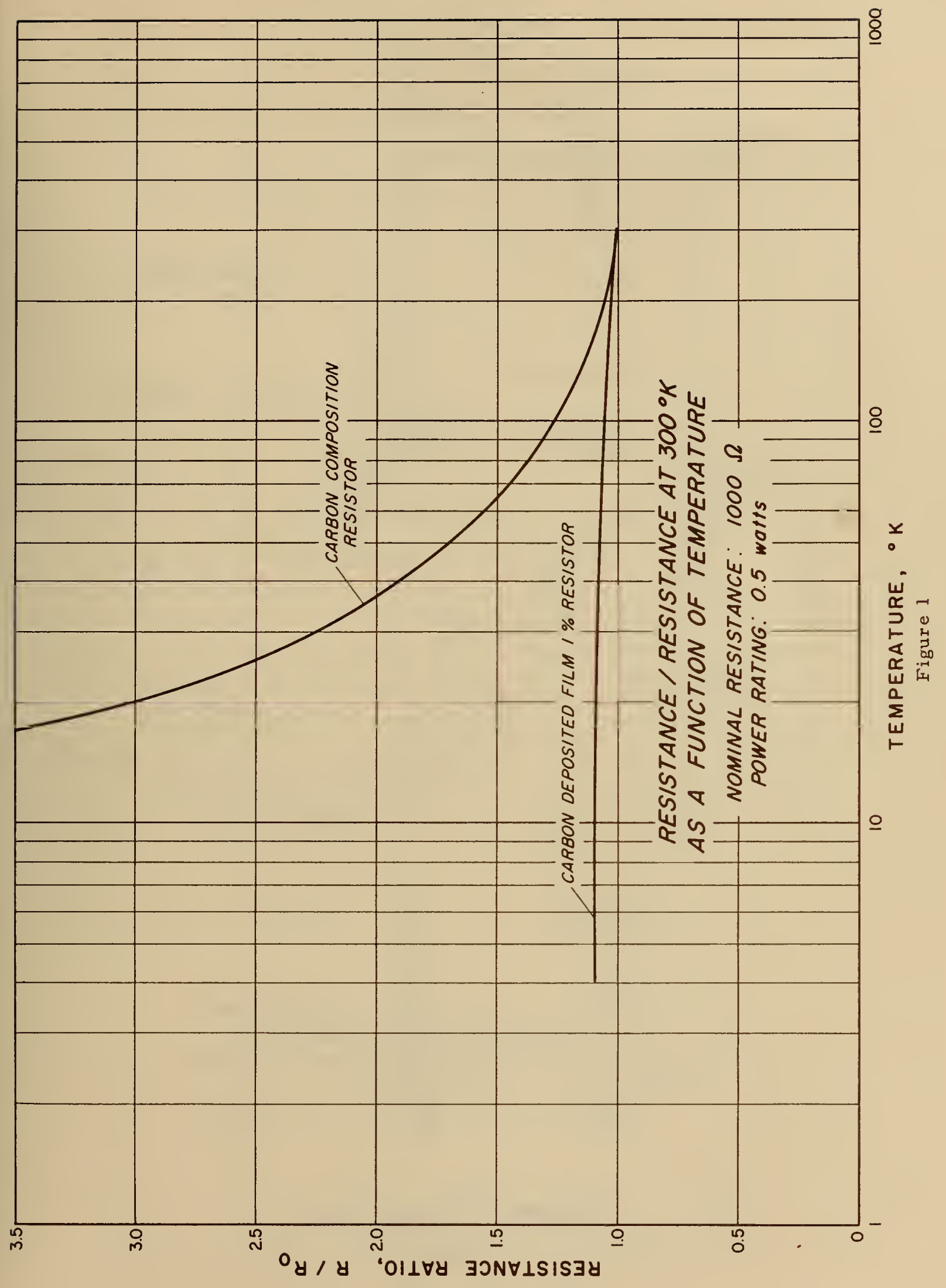




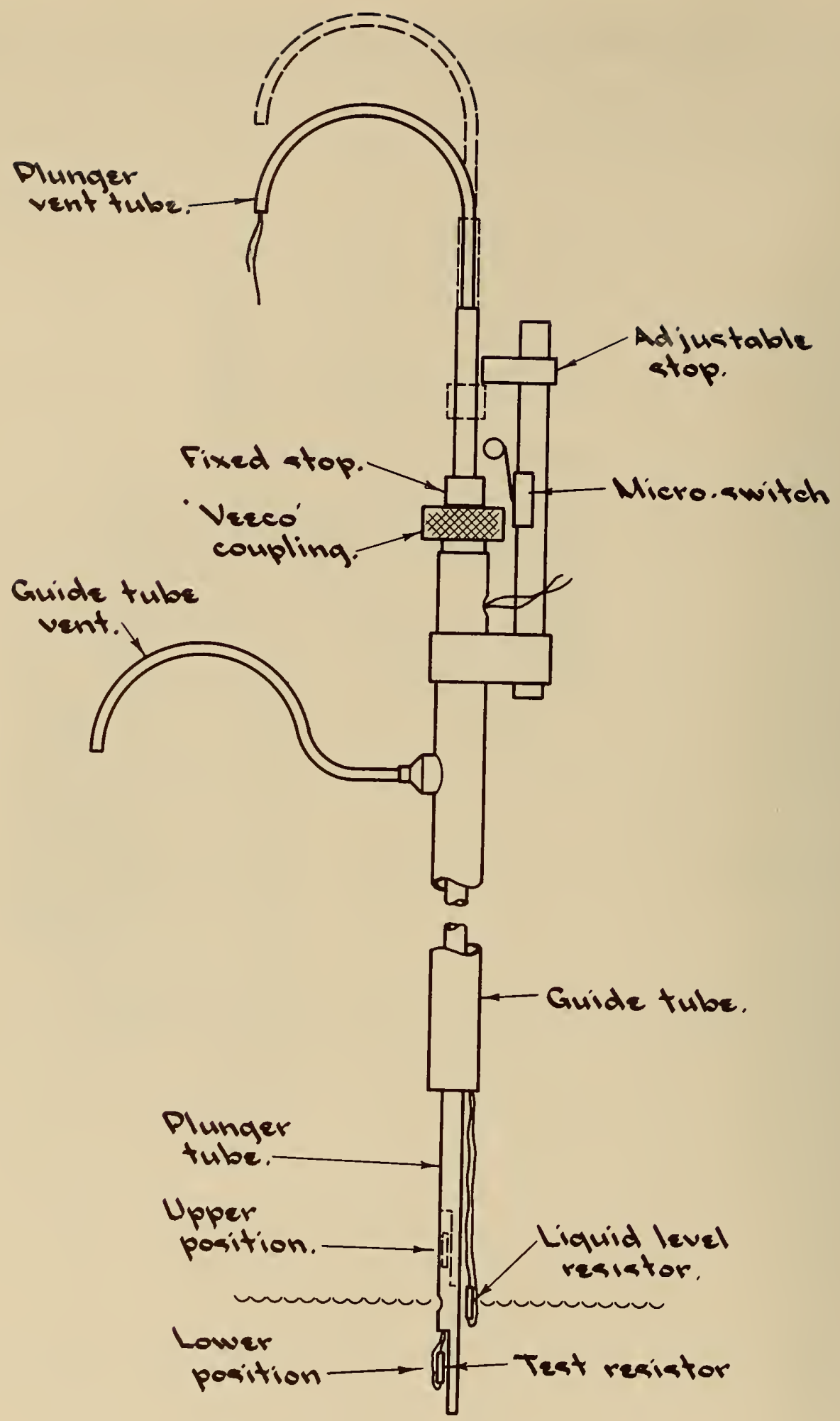

PROBE MGSEMBLY

Figure 2 


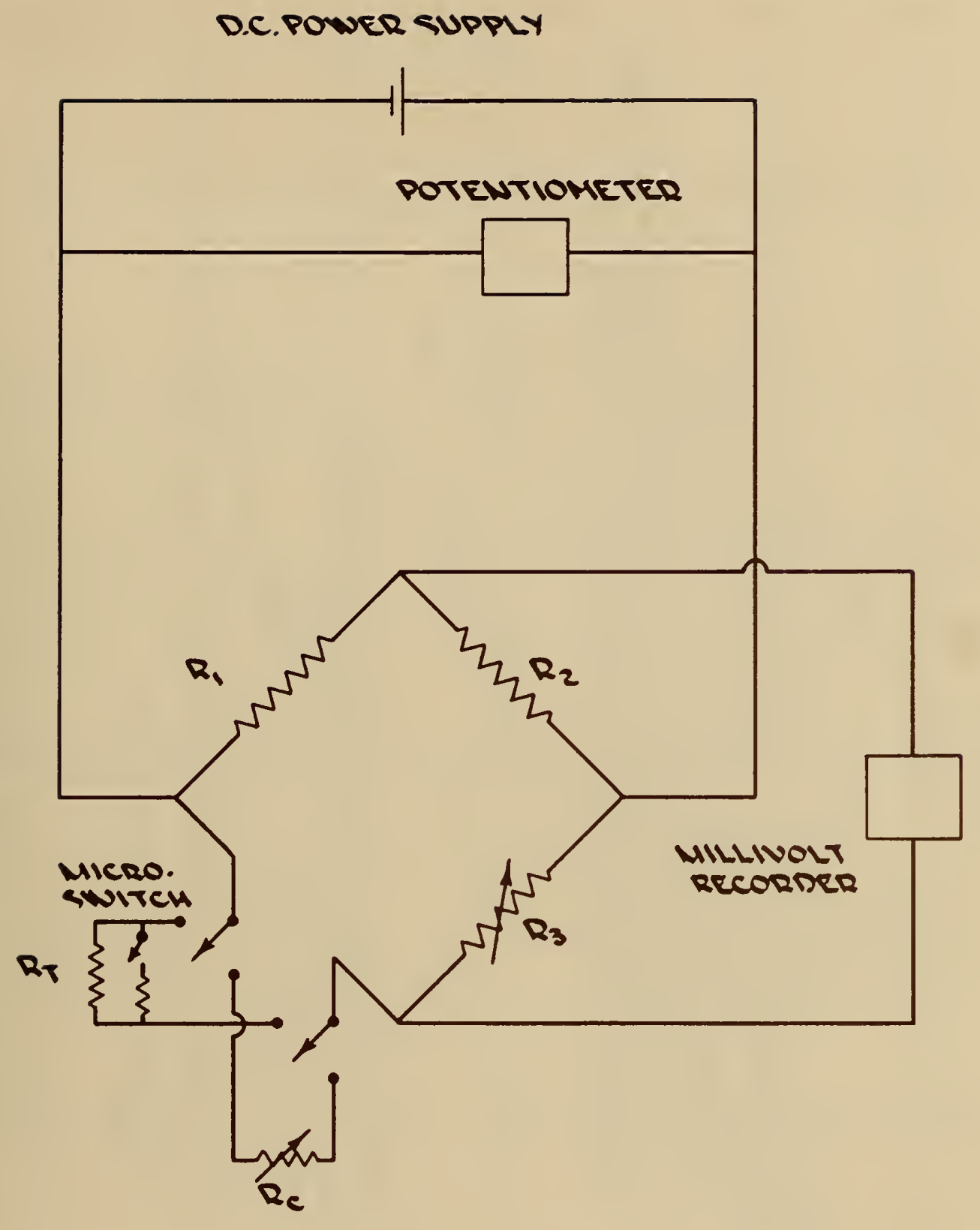

WIRING DUDGRAM of LANID LEVEL RESISTOR TESTS

Figure 3 


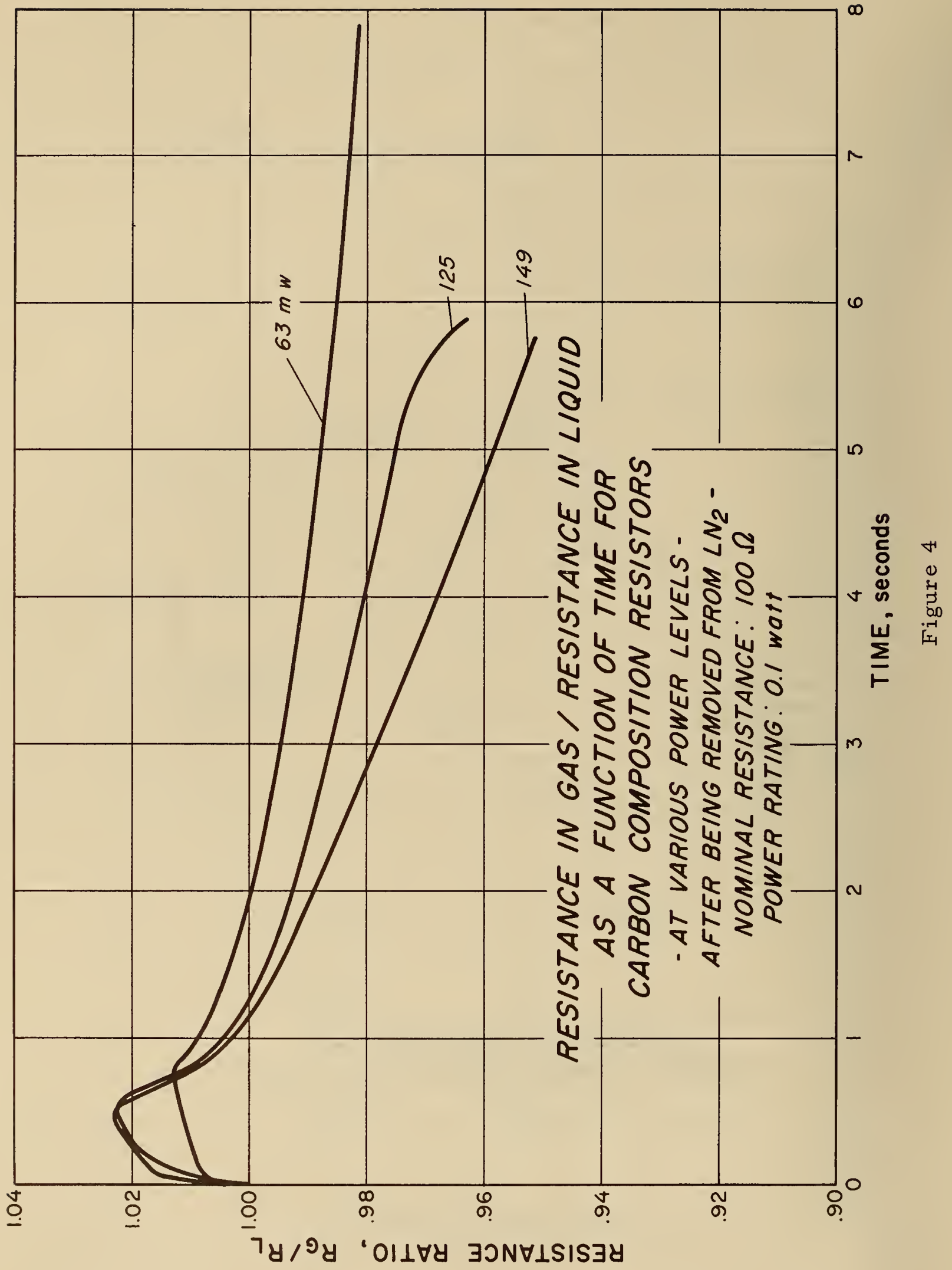




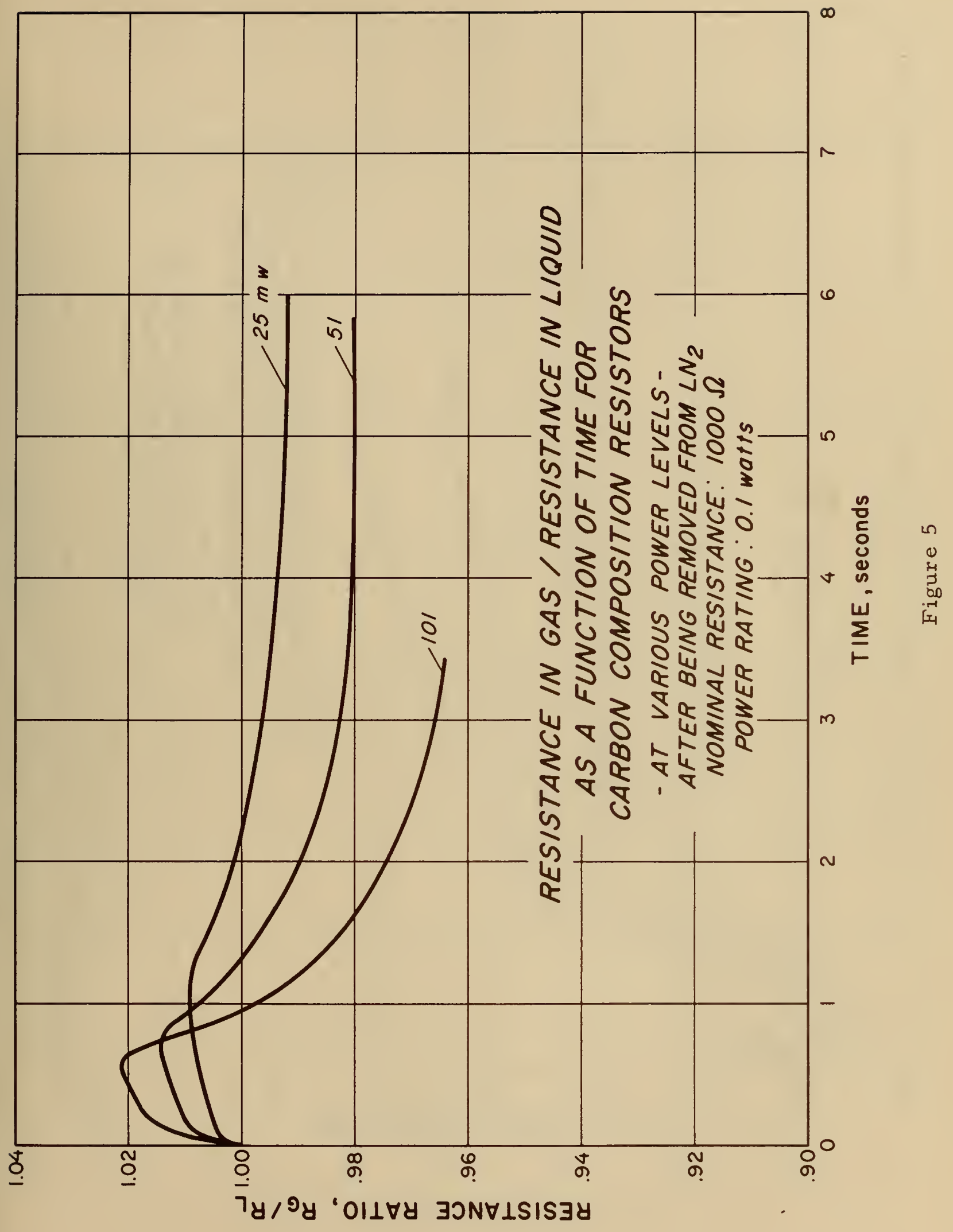




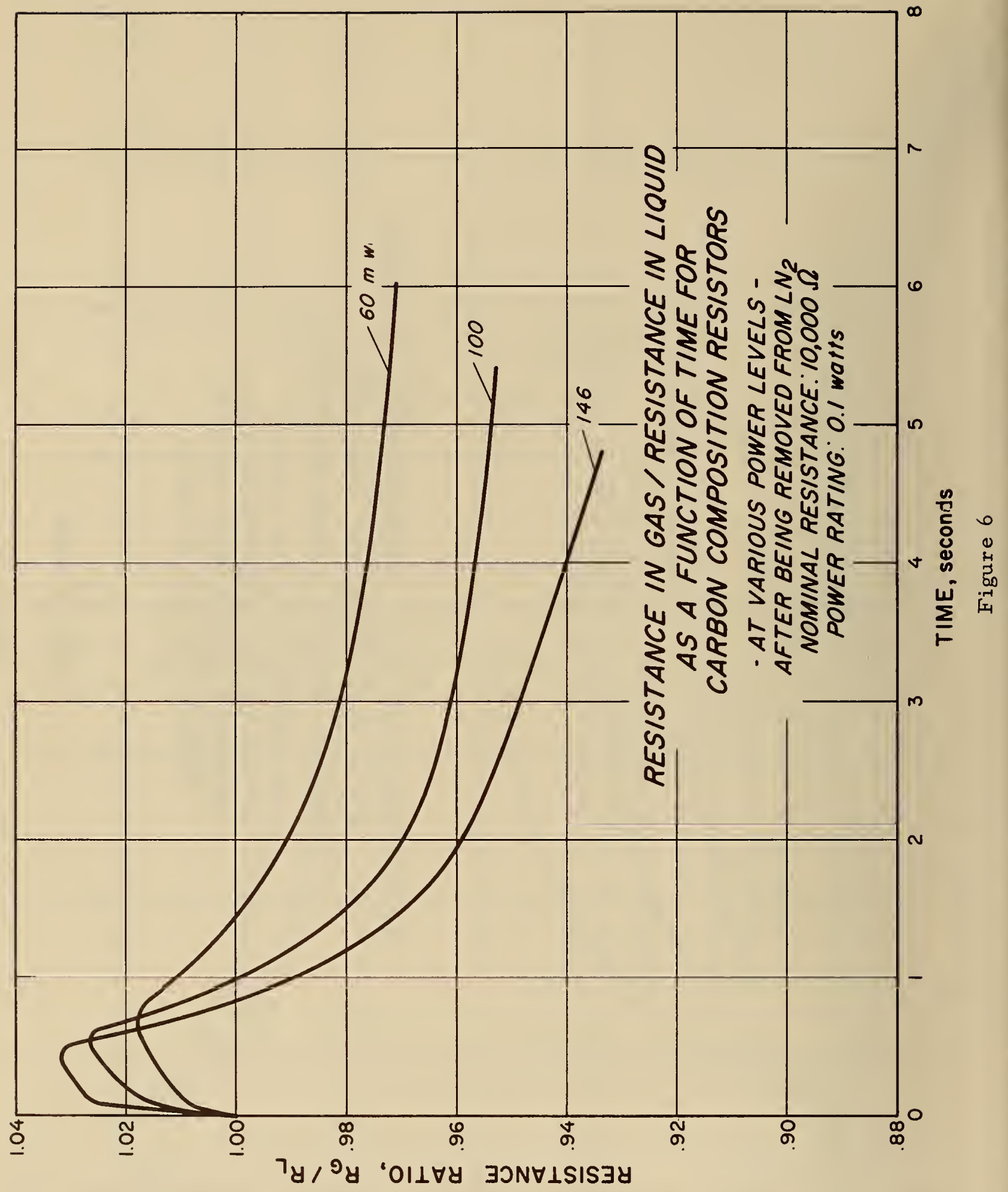




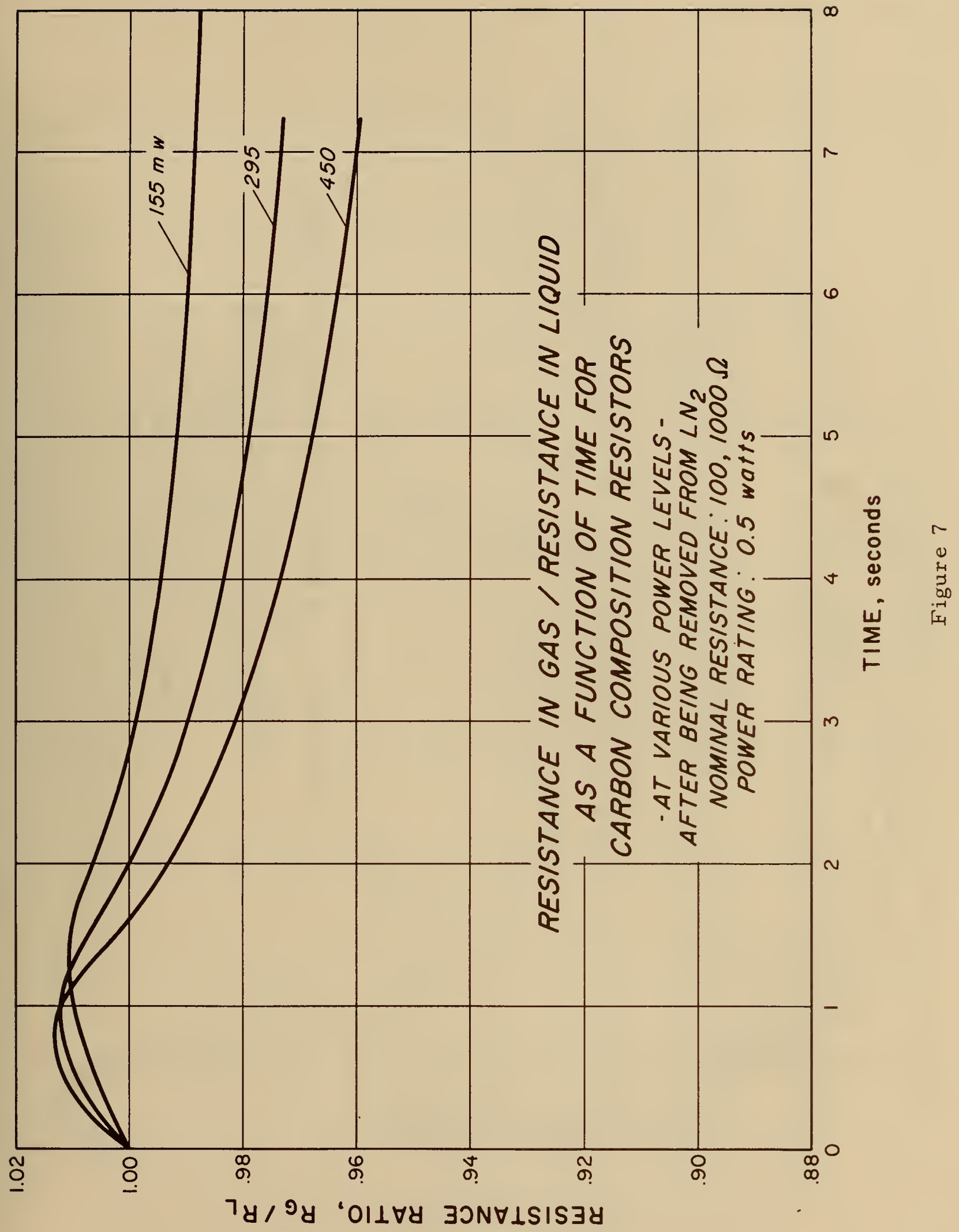




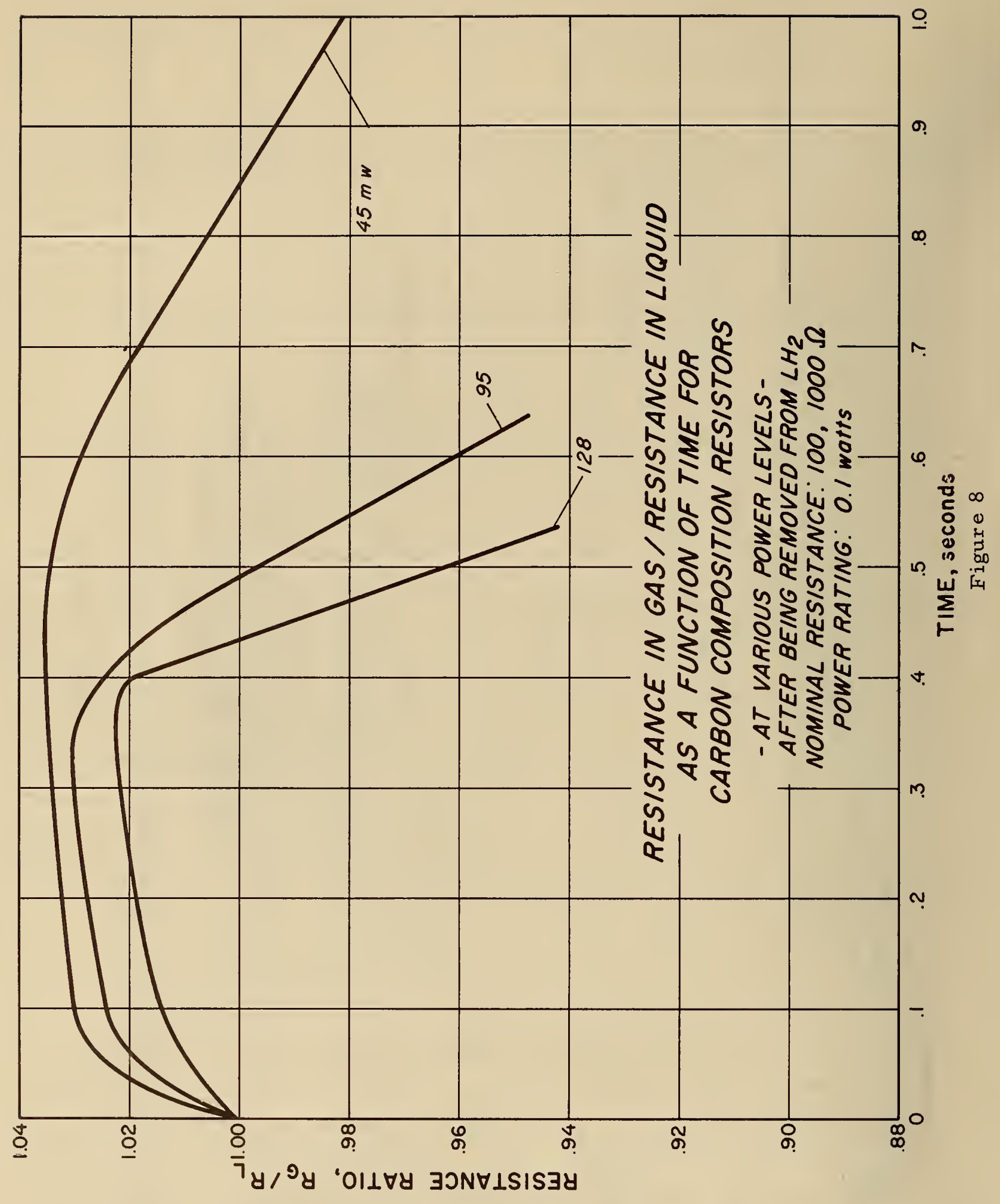




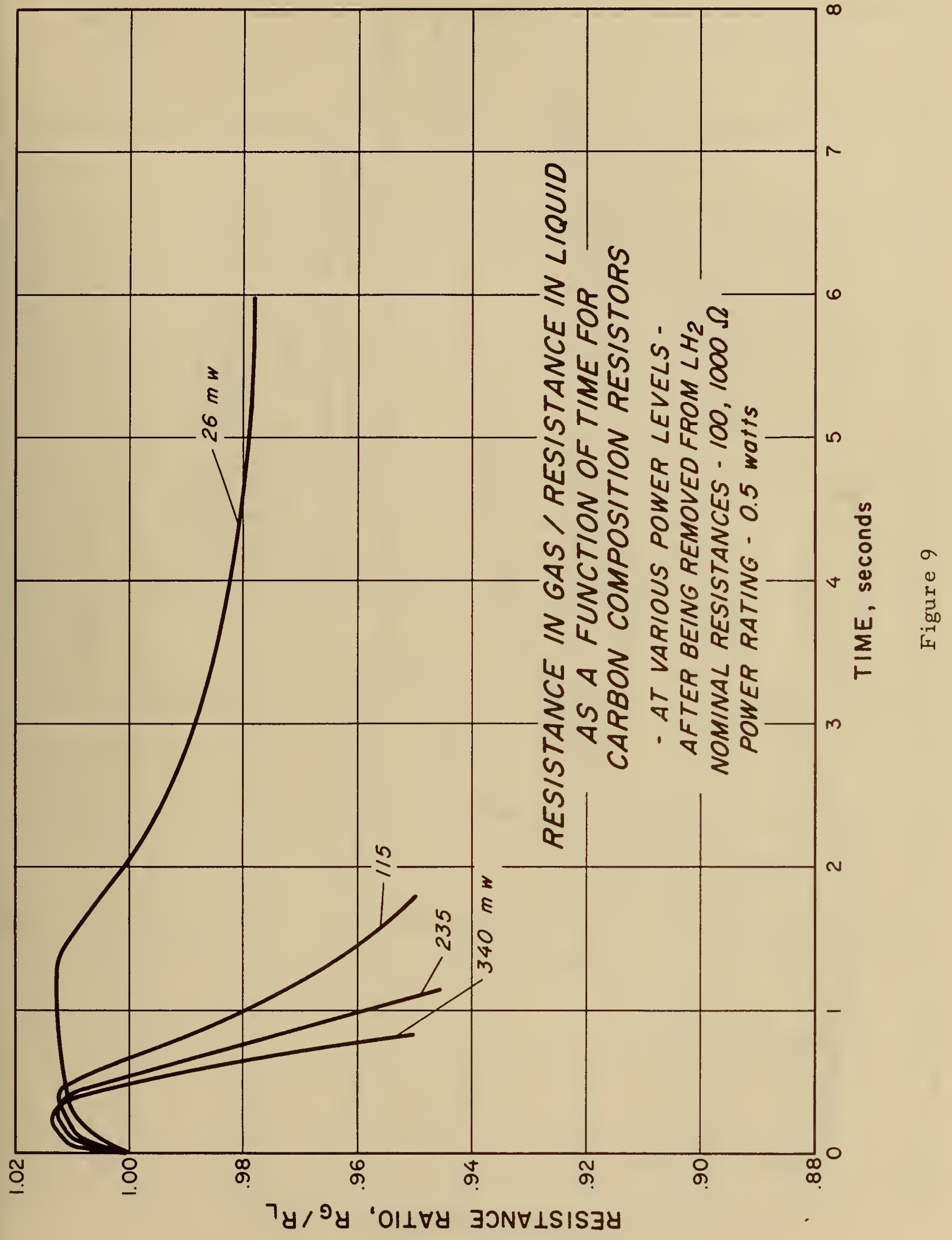




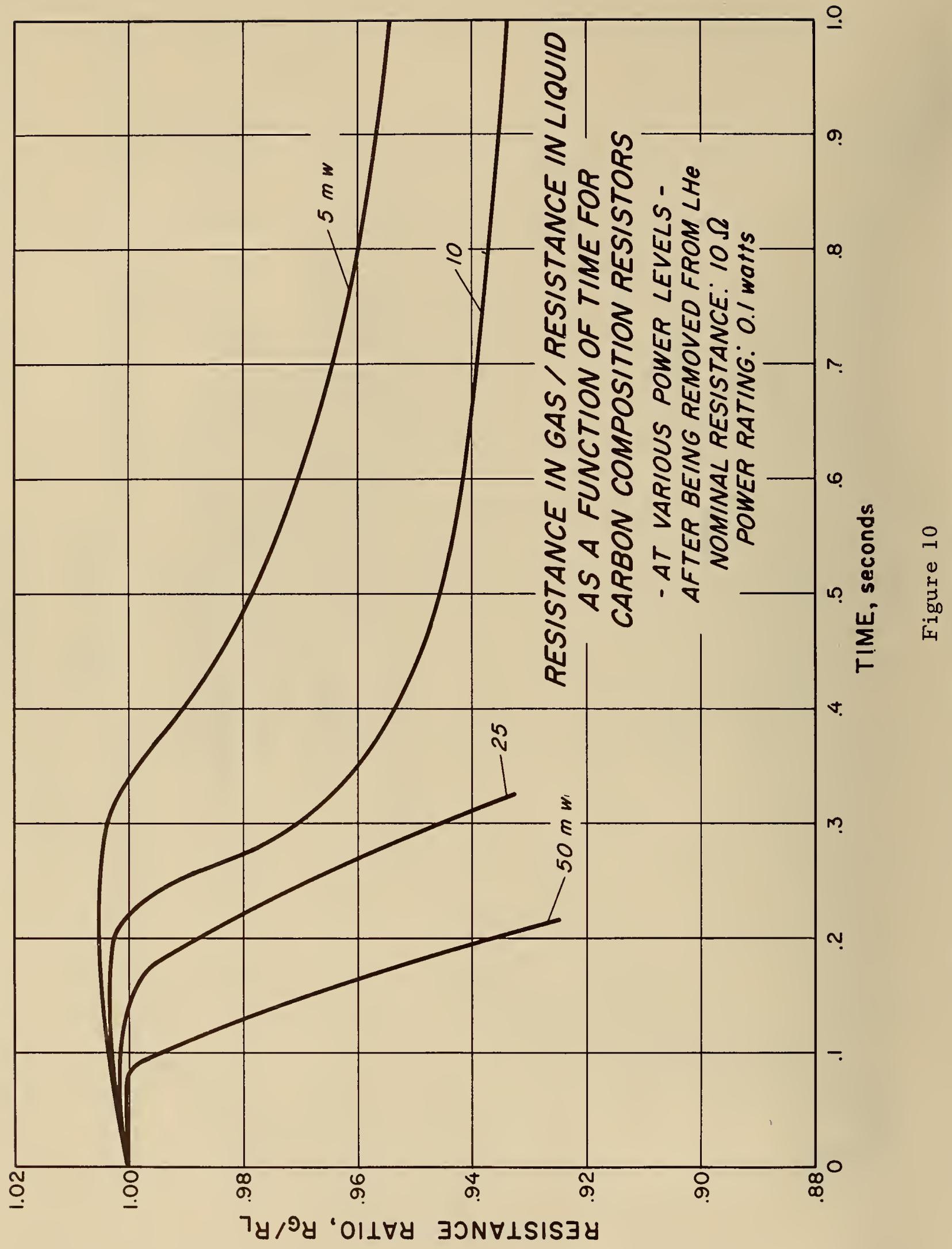




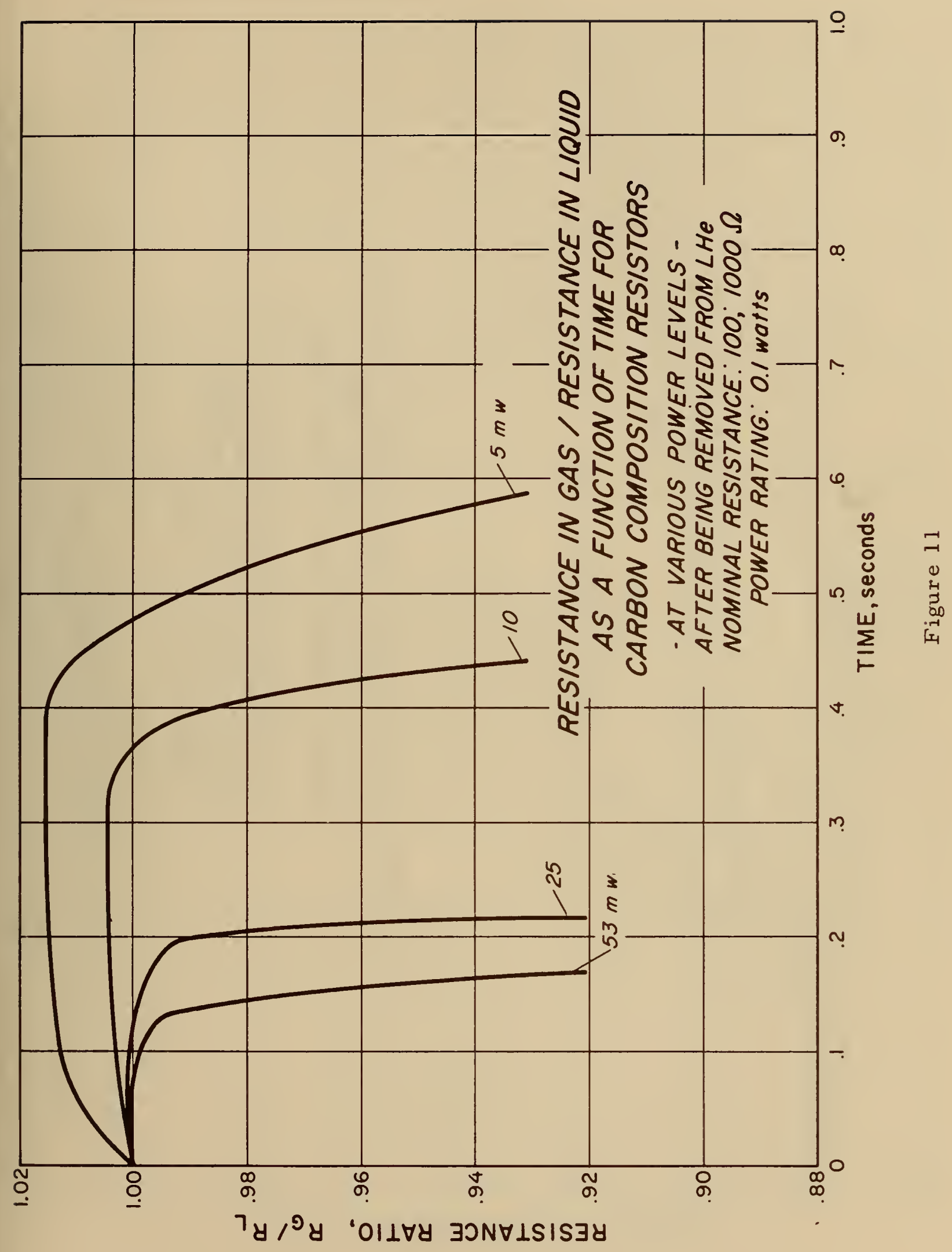




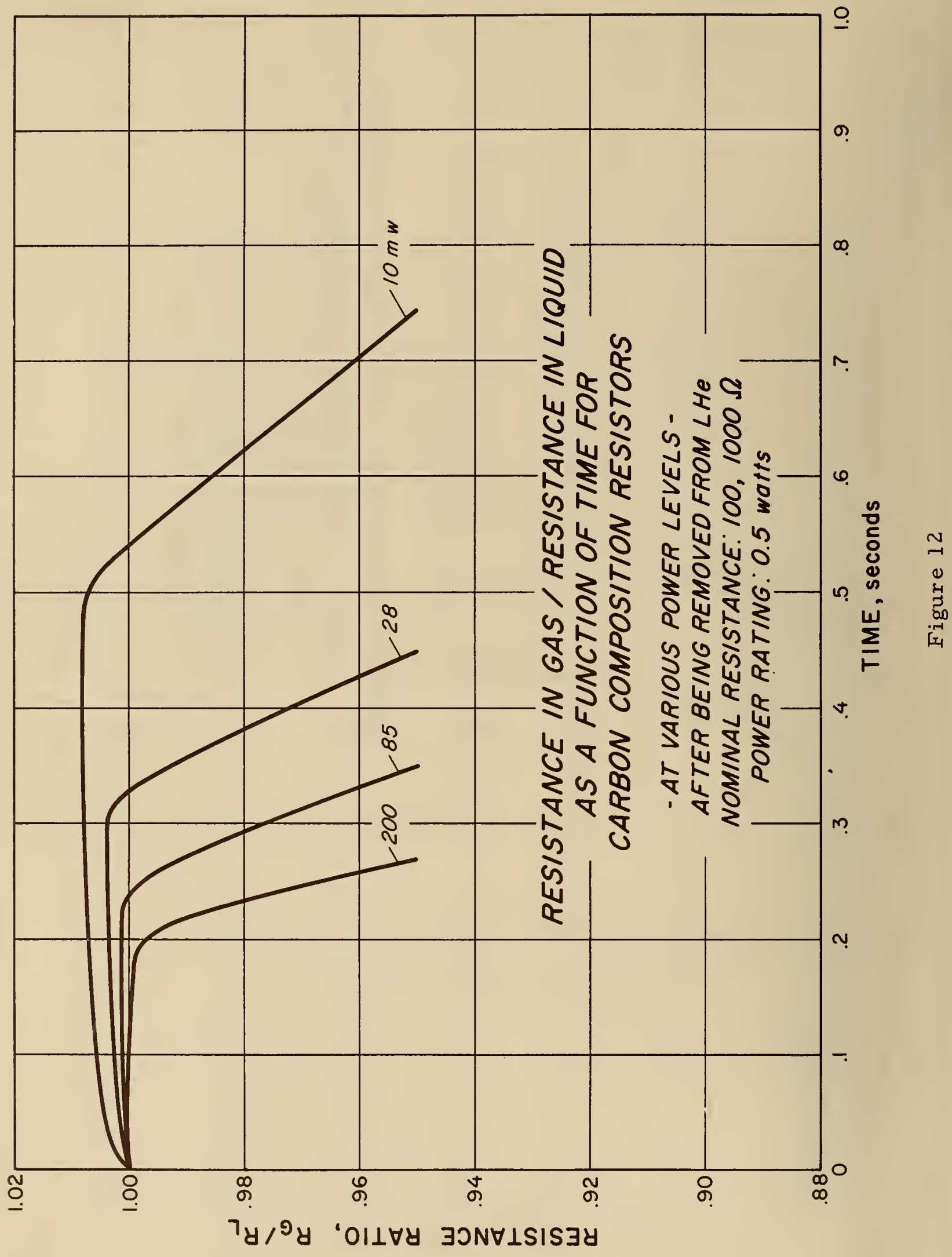




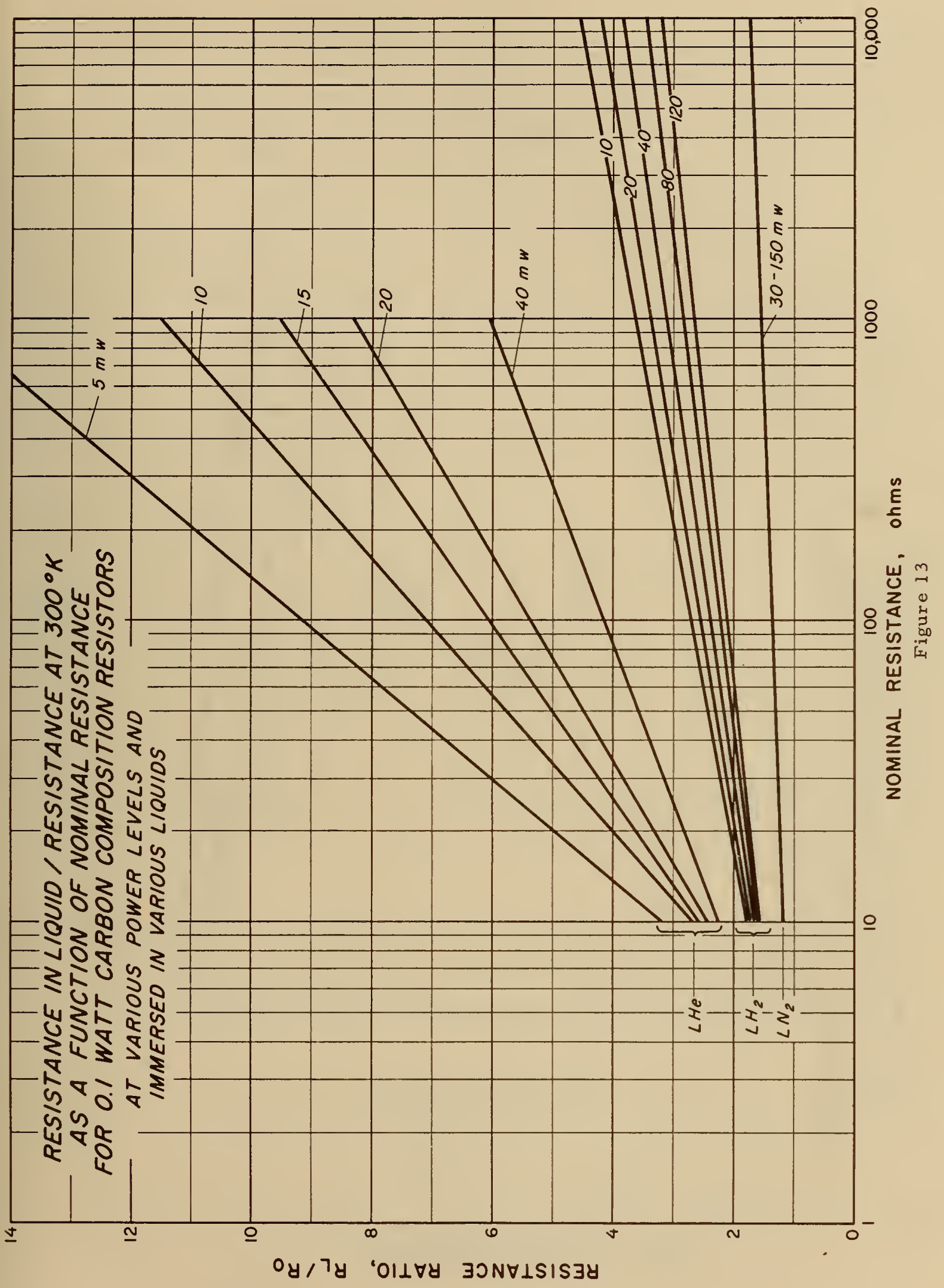




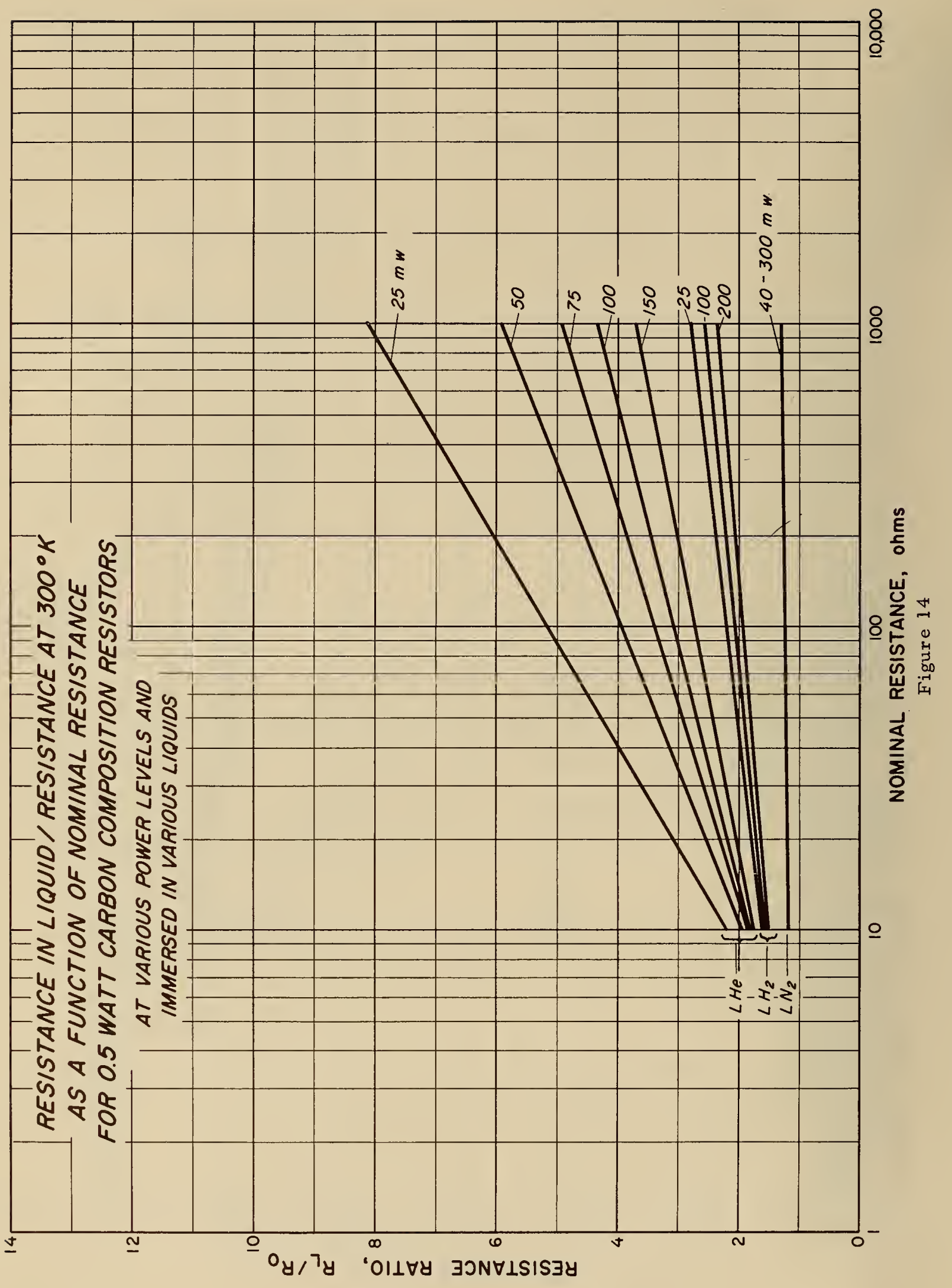


SENSOR

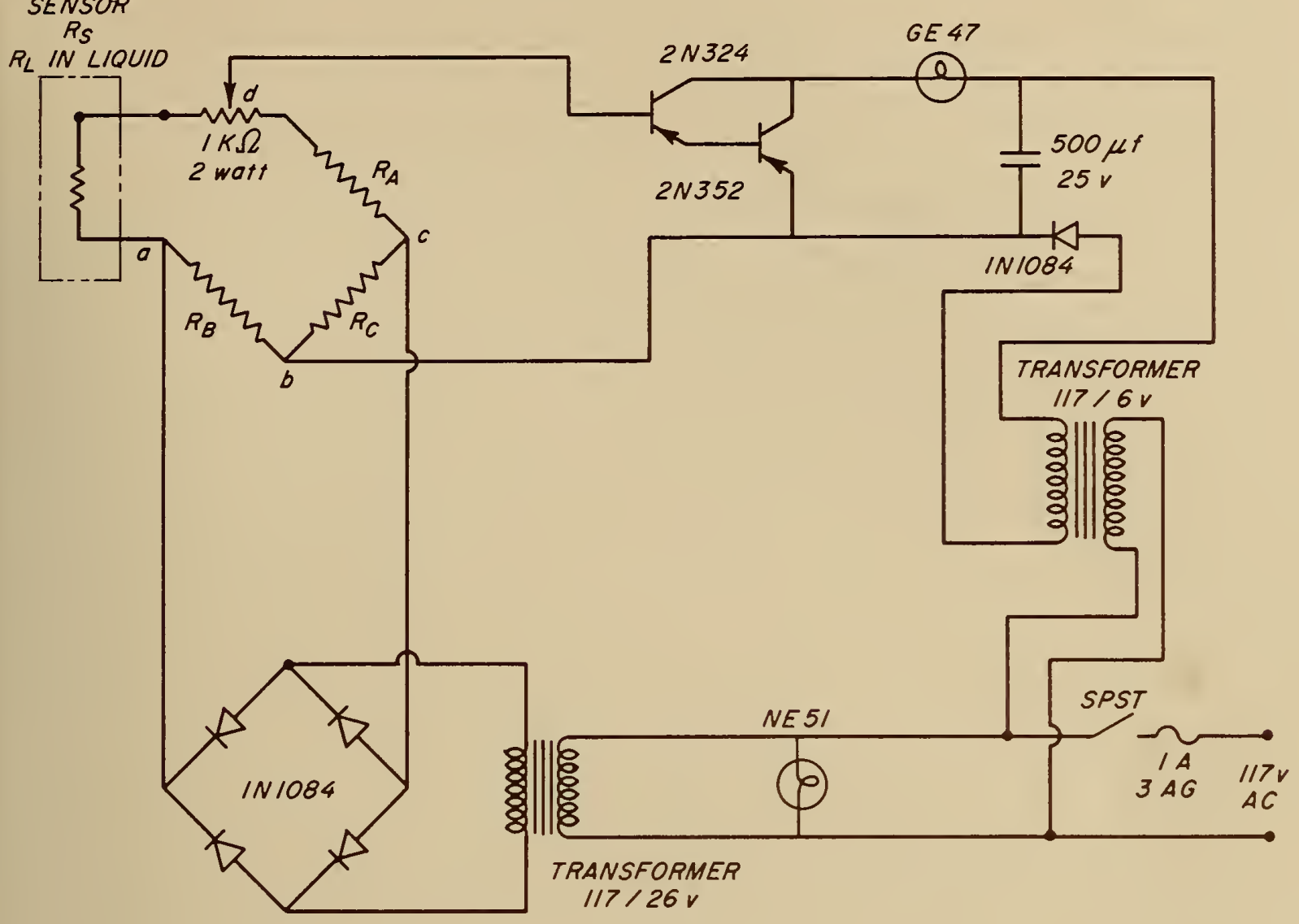

SCHEMATIC OF A LIQUID LEVEL INDICATOR

Figure 15-a

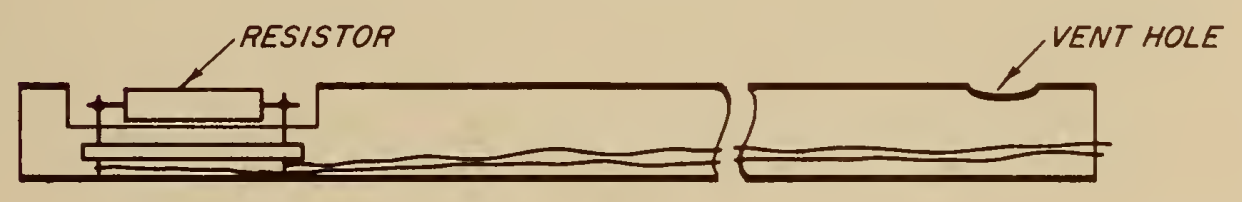

PROBE ASSEMBLY

Figure 15-b 




\section{U. S. DEPARTMENT OF COMMERCE \\ Luther H. Hodges, Secretary}

NATIONAL BUREAU OF ST ANDARDS

A.'V. Astin, Director

\section{THE NATIONAL BUREAU OF STANDARDS}

The scope of activities of the National Bureau of Standards at its major laboratories in Washington, D.C., and Boulder, Colorado, is suggested in the following listing of the divisions and sections engaged in technical work. In general, each section carries out specialized research, development, and engineering in the field indicated by its title. A brief description of the activities, and of the resultant publications, appears on the inside of the front cover.

WASIINGTON, D. C.

Electricity. Resistance and Reactance. Electrochemistry. Electrical Instruments. Magnetic Measurements. Dielectrics. High Voltage. Absolute Electrical Measurements.

Metrology. Photometry and Colorimetry. Refractometry. Photographic Research. Length. Engineering Metrology. Mass and Volume.

Heat. Temperature Physics. Heat Measurements. Cryogenic Physics. Equation of State. Statistical Physics. Radiation Physics. X-ray. Radioactivity. Radiation Theory. High Energy Radiation. Radiological Equipment. Nucleonic lnstrumentation. Neutron Physics.

Analytical and Inorganic Chemistry. Pure Substances. Spectrochemistry. Solution Chemistry. Standard Reference Materials. Applied Analytical Research. Crystal Chemistry.

Mechanics. Sound. Pressure and Vacuum. Fluid Mechanics. Engineering Mechanics. Rheology. Combustion Controls.

Polymers. Macromolecules: Synthesis and Structure. Polymer Chemistry. Polymer Physics. Polymer Characterization. Polymer Evaluation and Testing. Applied Polymer Standards and Research. Dental Research.

Metallurgy. Engineering Metallurgy. Metal Reactions. Metal Physics. Electrolysis and Metal Deposition. Inorganic Solids. Engineering Ceramics. Glass. Solid State Chemistry. Crystal Growth. Physical Properties. Crystallography.

Building Research. Structural Engineering. Fire Research. Mechanical Systems. Organic Building Materials. Codes and Safety Standards. Heat Transfer. Inorganic Building Materials. Metallic Building Materials.

Applied Mathematics. Numerical Analysis. Computation. Statistical Engineering. Mathematical Physics. Operations Research.

Data Processing Systems. Components and Techniques. Computer Technology. Measurements Automation. Engineering Applications. Systems Analysis.

Atomic Physics. Spectroscopy. Infrared Spectroscopy. Far Ultraviolet Physics. Solid State Physics. Electron Physics. Atomic Physics. Plasma Spectroscopy.

Instrumentation. Engineering Electronics. Electron Devices. Electronic lnstrumentation. Mechanical Instruments. Basic lnstrumentation.

Physical Chemistry. Thermochemistry. Surface Chemistry. Organic Chemistry. Molecular Spectroscopy. Elementary Processes. Mass Spectrometry. Photochemistry and Radiation Chemistry.

office of Weights and Measures.

BOULDEK, COLO.

\section{CRYOGENIC ENGINEERING LABORATORY}

Cry ogenic Processes. Cryogenic Properties of Solids. Cryogenic Technical Services. Properties of Cryogenic Fluids.

\section{CENTRAL RADIO PROPAGATION LABORATORY}

lonosphere Research and Propagation. Low Frequency and Very Low Frequency Research. lonosphere Rescarch. Prediction Services. Sun-Earth Relationships. Field Engineering. Radio Warning Services. Vertical Soundings Research.

Troposphere and Space Telecommunications. Data Reduction Instrumentation. Radio Noise. Tropospheric Measurements. Tropospheric Analysis. Spectrum Utilization Research. Radio-Meteorology. Lower Atmosphere Physics.

Radio Systems. Applied Electromagnetic Theory. High Frequency and Very High Frequency Research. Frequency Utilization. Modulation Research. Antenna Rescarch. Radiodetermination.

Upper Atmosphere and Space Physics. Upper Atmosphere and Plasma Physics. High Latitude lonosphere Physics. Ionosphere and Exosphere Scatter. Airglow and Aurora. Ionospheric Radio Astronomy.

\section{RADIO STANDARDS LABORATORY}

Radio Standards Physics. Frequency and Time Disseminations. Radio and Microwave Materials. Atomic Frequency and Time-Interval Standards. Radio Plasma. Microwave Physics.

Radio Standards Engineering. High Frequency Electrical Standards. High Frequency Calibration Services. High Frequency Impedance Standards. Microwave Calibration Services. Microwave Circuit Standards. Low Frequency Calibration Services.

Joint Institute for Laboratory Astrophysics-NBS Group (Univ. of Colo.). 
NBS 